Boletín de la Sociedad Geológica Mexicana

VOLUMen 61, NÚM. 3, 2009, P. 403-417

\title{
Estratigrafía de la Formación El Morro del Paleoceno-Eoceno en Zimapán, Hidalgo
}

\author{
Baldomero E. Carrasco-Velázquez ${ }^{*}$, Enrique Martínez-Hernández ${ }^{2}$ \\ y Elia Ramírez-Arriaga ${ }^{2}$
}

${ }^{1}$ Facultad de Ingeniería

Universidad Nacional Autónoma de México

Ciudad Universitaria, 04510, México, D.F.

${ }^{2}$ Instituto de Geología

Universidad Nacional Autónoma de México

Ciudad Universitaria, 04510, México, D.F.

*bcar@prodigy.net.mx

\begin{abstract}
Resumen
En la cuenca cretácica de Zimapán la orogenia Laramide generó una fase compresiva que propició la emersión y levantamiento del área. A medida que las rocas de la región ascendieron, se inició la erosión y quedaron conformadas algunas cuencas continentales intermontanas con una orientación que corresponde con las alineaciones de las estructuras plegadas mayores del área. Los episodios de sedimentación continental de tipo aluvial y fluvial en estas cuencas están representados por la Formación El Morro, que en su localidad tipo mide 64 metros y se divide en cuatro litofacies de acuerdo con sus diferentes componentes clásticos. Según estudios estratigráficos en la región, el espesor de la columna de sedimentos de la Formación El Morro varía desde algunos metros hasta cerca de 400 metros, con variaciones laterales drásticas. La sedimentación de la Formación El Morro fue seguida por la acumulación de una sucesión de brecha andesítica de la Formación Las Espinas. Estas dos unidades se interdigitan localmente por unos cuantos metros y se observan clastos de andesita en la cima de la Formación El Morro los cuales fueron fechados por K/Ar obteniéndose una edad de 38.1 $\pm 1.4 \mathrm{Ma}$. La edad de actividad de la cobijadura Jiliapán-El Volantín ubicada a $25 \mathrm{Km}$ al norte de Zimapán es de 62 Ma, y fue determinada en la ilita diagénetica, lo que restringe la deformación activa compresiva al Paleoceno inferior e indica el final de la orogenia. En consecuencia la edad de la Formación El Morro es limitada al menos al Paleoceno medio-Eoceno medio mediante la edad isotópica por K-Ar de las rocas volcánicas suprayacentes y la ilita formada en el movimiento de la cobijadura Jiliapán-El Volantín. El estudio palinológico indica un ambiente calido-humedo, que propició la formación de un ambiente fluvial.
\end{abstract}

Palabras clave: Rocas sedimentarias, Paleoceno medio-Eoceno medio, palinología, Zimapán.

\begin{abstract}
The Cretaceous Zimapan basin was affected by compressive Laramide deformation, which gave place to tectonic uplift in the area. After regional uplift of the rocks, erosion began to fill several continental intermontane basins with an orientation parallel to the alignment of the major folded structures. The "El Morro Formation" represents the alluvial and fluvial filling of the intermontane basins. El Morro Formation type locality has a stratigraphic thickness of 64 meters and is composed of four lithofacies with different source rocks. The earliest stratigraphic work in Zimapan area described a stratigraphic thickness that varies from several meters to 400 meters with drastic lateral changes. Sedimentation of the El Morro Formation was interrupted by the accumulation of a succession of andesitic breccias of Las Espinas Formation. Both formations are locally interfingered by a few meters and the top of El Morro Formation includes andesitic clasts, which gave a K/Ar age of 38.1 $1.4 \mathrm{Ma}$. An age of $62 \mathrm{Ma}$ was obtained in diagenetic illite from
\end{abstract}


the Jiliapan-El Volantin thrust fault, located $25 \mathrm{~km}$ north of Zimapan, which constrains the end of active compressive deformation to the earliest Paleocene. The age of the El Morro Formation ranges from at least the middle Paleocene to middle Eocene by the K/Ar isotopic age of the overlying volcanic rocks and the diagenetic illite formed during the movement of the Jiliapan-El Volantin thrust faults. The palynological assemblages indicate a tropical climate with abundant precipitation and confirm the fluvial regimen that prevailed during the deposition of El Morro Formation.

Keywords: Sedimentary rocks, middle Paleocene-middle Eocene, palynology, Zimapan.

\section{Introducción}

Zimapán,se sitúa en la Sierra Madre Oriental, que es una cordillera formada fundamentalmente por rocas sedimentarias marinas mesozoicas que fueron deformadas por acortamiento durante la orogenia Laramide, su actividad produjo pliegues y cabalgaduras, cuya edad no está bien definida, pero en las cercanías de Zimapán abarca probablemente desde el Cretácico Tardío (Suter, 1990) hasta el Paleoceno Temprano (Gray et al., 2001). Los primeros reportes de la Formación El Morro se encuentran en Simons y Mapes (1957), quienes en una localidad a $6 \mathrm{~km}$ al noroeste de Zimapán en el Cerro del Morro, describen unas rocas que forman laderas de pendientes fuertes y acantilados que llamaron fanglomerado El Morro, también así lo llamaron García y Querol (1991), e Yta y Moreno-Tovar (1997).

Algunos otros estudios hacen referencia a estas mismas rocas bajo otros términos litoestratigráficos, como Grupo El Morro lo citan Segerstrom (1961), Fries (1962) y Geyne et al. (1963), y como Formación El Morro Carrillo-Martínez y Suter (1982), Consejo de Recursos Minerales (1992), Servicio Geológico Mexicano (1997) y Carrillo-Martínez (1998).

Sin embargo, fueron Simons y Mapes (1957) quienes describieron con detalle las características litológicas generales de la Formación El Morro en su localidad tipo, cabe mencionar que todos los estudios posteriores se basan en los conceptos de dichos autores así como el de su correlación con el Conglomerado Rojo de Guanajuato, sin ningún apoyo paleontológico.

En este trabajo se redefine la litoestratigrafía de la Formación El Morro en la sección tipo, así como las condiciones de sedimentación asociadas a dichas capas, según los conceptos sobre la arquitectura de los depósitos y las litofacies de Miall, (1992, 1996), y los de Blair y McPherson (1994); asimismo, la edad es definida por el volcanismo suprayacente y la edad de generación de las cabalgaduras fechados por K-Ar; adicionalmente se analizan las asociaciones de polen y esporas que indican condiciones paleoclimáticas calidohumédas y el ambiente fluvial.

\section{Estratigrafía Pre-Cenozoica}

Las rocas jurásico-cretácicas más antiguas que afloran en la Cuenca de Zimapán (Simons y Mapes, 1957;
Segerstrom, 1961; Carrillo-Martínez y Suter, 1982; Carrillo-Martínez, 1998) pertenecen a la Formación Trancas (Kimeridgiano-Barremiano), formada por capas de 1 a $2 \mathrm{~m}$ de micrita fosilífera con radiolarios intercaladas con lutitas calcáreas y limolitas ligeramente apizarradas. Su color es grisáceo amarillento, con algunas capas de arenisca gruesa, color café rojizo que consisten en litarenita feldespática con detritos de rocas ígneas y metamórficas. Según Carrillo-Martínez, (1998) el espesor de la Formación Trancas en el anticlinal El Chilar es de $1000 \mathrm{~m}$.

Sobreyaciendo a la Formación Trancas se encuentra la Formación Tamaulipas Superior, fechada inicialmente por Boese (1923) con amonitas como de edad Albiana, después Carrillo-Martínez y Suter (1982) en su área de estudio dan una edad Aptiana-Cenomaniana. Estos autores calculan para dicha formación un espesor estratigráfico de entre 300 y $1200 \mathrm{~m}$, y la describen como una unidad constituida por capas de 60 a $150 \mathrm{~cm}$ de micrita fosilífera y biomicrita de foraminíferos planctónicos y calciesferas su color es gris claro a gris oscuro y es común encontrar una estructura boudinada, con laminación y sedimentación gradual. Existe pedernal negro en bandas delgadas y nódulos.

Según Carrillo-Martínez y Suter (1982) y CarrilloMartínez (1998), las Formaciones Soyatal-Mendez no son diferenciadas en Zimapán y pueden tener en conjunto al menos $1000 \mathrm{~m}$ de espesor, con una edad determinada por macrofósiles y microfósiles como del Turoniano-Campaniano; con estratos que se caracterizan por numerosos pliegues sinsedimentarios y estructuras 'nodulares' (boudinage sinsedimentario) causados por ruptura y flujo de la roca no consolidada.

En realidad, en algunos afloramientos es posible reconocer ciertas diferencias petrográficas y de intemperismo entre ambas formaciones. Entre los caracteres litológicos correspondientes a la Formación Soyatal, destacan las capas de micrita fosilífera de color gris oscuro, interestratificadas con lutitas calcáreas de color gris, las dos intemperizan de manera uniforme en colores variables entre el gris, el amarillento y un verde grisáceo; también hay algunas capas delgadas de limolitas de color rojizo a rojo intenso. Sobreyaciendo a las rocas anteriores se encuentran capas de 60 a $70 \mathrm{~cm}$ de lutita calcárea verde clara, interestratificadas con capas de micrita fosilífera gris oscuro de 40 a 50 $\mathrm{cm}$ de espesor, y con margas azul-verde de aspecto lajeado, las cuales son semejantes a la Formación Méndez. 
Las capas de la Formación Soyatal son más resistentes al intemperismo y forman montículos, mientras que la Formación Méndez constituye laderas arcillosas de poca pendiente; ambas formaciones contienen amonitas.

\section{Estratigrafía de la Formación El Morro}

En el cerro El Morro, suprayaciendo en discordancia angular a las rocas mesozoicas marinas de la Formación Soyatal-Méndez [sensu Carrillo-Martínez (1998)], se encuentra la Formación El Morro constituida por una secuencia de rocas sedimentarias continentales conglomeráticas, hacia la cima la secuencia es interrumpida por rocas volcánicas que marcan un cambio del medio de depósito.

La distribución geográfica de la Formación El Morro está restringida al oeste y noroeste de Zimapán (Figura 1), la localidad tipo en el cerro El Morro (6 Km al noroeste de Zimapán) está situada en una franja orientada NW-SE de aproximadamente $11 \mathrm{Km}$ de largo y anchuras de entre 3 y
$0.5 \mathrm{Km}$, su orientación corresponde con las alineaciones de las estructuras plegadas mayores del área. Una segunda franja se localiza al oeste de la anterior con una longitud de $4 \mathrm{Km}$ y menos de $1 \mathrm{Km}$ de ancho. Estas franjas corresponden con la formación de cuencas intermontanas, que se construyeron en las depresiones estructurales entre las montañas, configurando valles rellenados por sedimentos aluviales y fluviales.

La conformación de cuencas intermontanas ocurrió después de los eventos laramídicos en varias partes de las montañas rocallosas como por ejemplo en la cuenca de Uinta, donde Andersen y Picard (1973) señalan que durante el Eoceno (40 Ma) dicha cuenca se relleno de conglomerados heterogéneos pobremente estratifícados y lentes de arenisca. Las rocas de la Formación El Morro y las de la cuenca de Uinta podrían ser correlacionadas en tiempo y origen.

De acuerdo con Simons y Mapes (1957) el espesor de la Formación El Morro es variable, desde unos cuantos
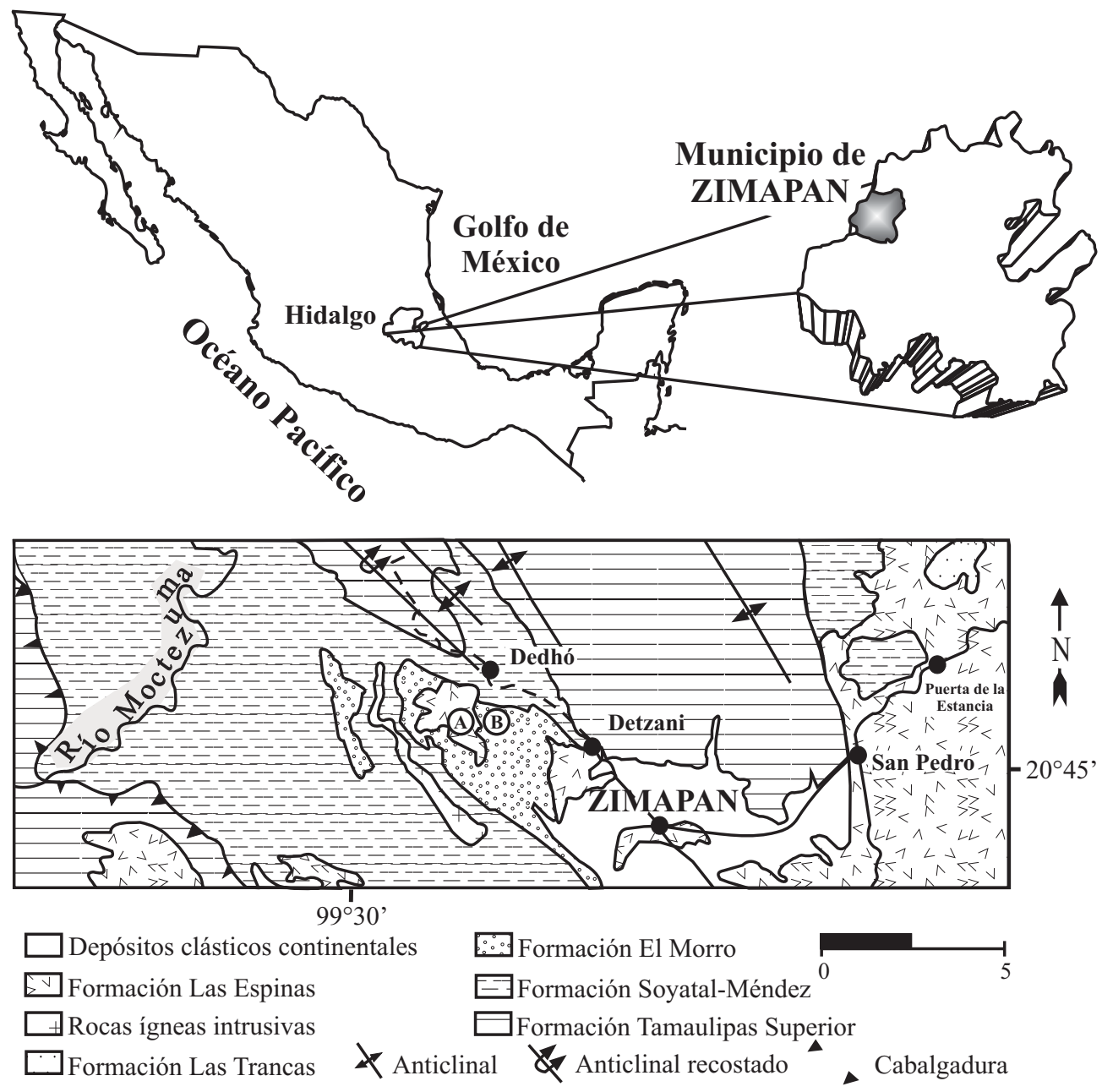

Figura 1. Localización y geología local [modificada de Carrillo y Suter (1982); Carrillo, (1998) y Carrillo et al. (2001)]. Afloramientos al noroeste de Zimapán, de los cerros El Morro (localidad B) y Las Espinas (localidad A). 
metros hasta cerca de $400 \mathrm{~m}$, y descansa en forma discordante sobre calizas y lutitas del Cretácico Superior, o sobre las calizas del Cretácico Inferior. Según estos autores la litología de la Formación El Morro es uniforme a través del área, y se trata de rocas de color rojizo, gris rojizo o gris-purpúreo, muy bien consolidada y compuesta casi en su totalidad por guijas y pedrejones de caliza gris, y menos comúnmente de caliza parda con formas que varían de angulosas a subangulosas, no se encontraron fósiles; su edad probable se consideró como Eoceno-Oligoceno temprano por su semejanza litológica con el conglomerado rojo de Guanajuato descrito por Edwards (1955). También Segerstrom (1961) comenta que en ninguna de las localidades de la Formación El Morro encontraron fósiles que permitieran determinar su edad, pero que podría correlacionarse con el Conglomerado Rojo de Guanajuato.

Para Carrillo-Martínez (1998) la litología más representativa de la Formación El Morro son "clastos de diferentes tamaños, angulosos a subredondeados, de caliza, marga y lutita en una matriz arenosa de composición carbonatada y silicea."

Las rocas ígneas de la Formación Las Espinas cubren a la Formación El Morro, y según Simons y Mapes (1957) se interdigitan localmente con las capas de la cima de esta última formación. La Formación Las Espinas está formada por tobas y lavas andesiticas, las cuales alcanzan un espesor de $250 \mathrm{~m}$ en el Cerro de Las Espinas, situado al oeste del Cerro del Morro.

Las diferentes corrientes de lavas en el Cerro de Las Espinas (Simons y Mapes, 1957) varían de 3 a 4 m de espesor, alcanzando hasta $10 \mathrm{~m}$, tienen una matriz parcialmente cristalina, las plagioclasas son comúnmente los únicos fenocristales identificables megascópicamente.

La edad de las andesitas de la Formación Las Espinas ha sido confusa, porque Simons y Mapes (1957) fijaron su edad con base en la relación de sobreyaciencia con la Formación El Morro, infiriendo su equivalencia en edad con el Conglomerado de Guanajuato el cual inicialmente fue asignado al Eoceno-Oligoceno temprano (Edwards, 1955); y posteriormente se restringió al Eoceno mediotardío por Ferrusquía (1987) y al Eoceno medio por NietoSamaniego (1992).

La problemática de estas edades, tanto de las rocas volcánicas de la Formación Las Espinas como de la Formación El Morro, se ha venido esclareciendo gracias a la edad isotópica en clastos de la Formación Las Espinas contenidos en la parte superior de la Formación El Morro, como se discute a continuación.

La litología de las rocas de la Formación Las Espinas es variada, así, las lavas del área del Cerro de las Espinas son porfídicas y tienen una matriz parcialmente cristalina. Según la descripción de Simons y Mapes, (1957) son principalmente andesíticas, con una menor proporción de lavas basálticas.

En relación a las edades isotópicas de rocas que se han considerado como Formación Las Espinas se pueden hacer las siguientes observaciones: 1) Cantagrel y Robin (1979) en una muestra de andesita marcada como ZI 43, colectada en el Puerto de la Estancia al noreste de Zimapán obtuvierón una edad del Mioceno tardío $(9 \pm 0.30 \mathrm{Ma})$; debido a que en dicha área no existen rocas de la Formación El Morro, se estima que la muestra no pertenece a la Formación Las Espinas sino a rocas volcánicas más jóvenes, 2) García y Querol (1991) a propósito de la Formación Las Espinas dicen: "Las Espinas aflora al sur del distrito minero con un espesor mayor a los $150 \mathrm{~m}$, en su base se interdigita con el Fanglomerado El Morro lo cual las hace contemporáneas. No se han determinado edades absolutas", en otro párrafo: "La actividad ígnea en el distrito fue en su mayor parte de magmatismo del Oligoceno temprano (38.7 $\pm 0.8 \mathrm{Ma}$; Gaytán, 1957) representado principalmente intrusivos monzoniticos con predominancia de volcánicos intermedios", 3) Yta y Moreno-Tovar (1997), describen que un conglomerado epicontinental conocido como Fanglomerado El Morro, es un conglomerado fluvio-lacustre que se interdigita con algunos niveles volcánicos; más adelante dicen que una unidad volcánica andesítica, que yace sobre el Fanglomerado El Morro en Zimapán, se ha descrito como Formación Las Espinas, con edades de 38 a $27 \mathrm{Ma}$, correspondientes al Oligoceno, y 4) en el reporte JICA-CRM (1980), las rocas ígneas extrusivas de la Formación Las Espinas, nombrada como "Altered andesite lava (Tan1)", son descritas de la siguiente manera: "las rocas suelen tener una coloración gris-verdosa, como de una toba brechoide que en realidad es una lava andesítica, la cual incluye muchos fragmentos consanguíneos" tiene una edad absoluta por K-Ar del Eoceno Superior (38.1 1.4 Ma). En el mismo reporte se describe que en la Formación El Morro, llamada "Conglomerate (Tcg)", en su contacto con la Formación Las Espinas se encontraron los cantos de andesita que proceden de la actividad volcánica (Tan 1), lo que hace posible deducir una edad máxima del Eoceno superior para la cima de la Formación El Morro.

\section{Palinología}

En total se tomaron seis muestras de la base a la cima, en la figura 2 se pueden observar los diferentes niveles de muestreo. Previamente a la toma de muestras se llevó a cabo la limpieza de la superficie hasta un metro de profundidad para poder llegar a la roca no intemperizada. En el caso particular de este tipo de conglomerados, en el laboratorio se procedió mecánicamente a separar los clastos de todos tamaños a fin de obtener únicamente la matriz, la cual fue procesada con las técnicas estándares empleadas en palinología, que consisten en la maceración química de la matriz con acido clorhídrico, y acido flurhídrico. De esta manera, se asegura que la mayoría de los palinomorfos obtenidos provienen de la matriz y que fueron depositados penecontemporaneamente con los clastos que constituyen los conglomerados. Se procesaron 40 gramos de matriz y la recuperación.de palinomorfos fue buena, ya que se 


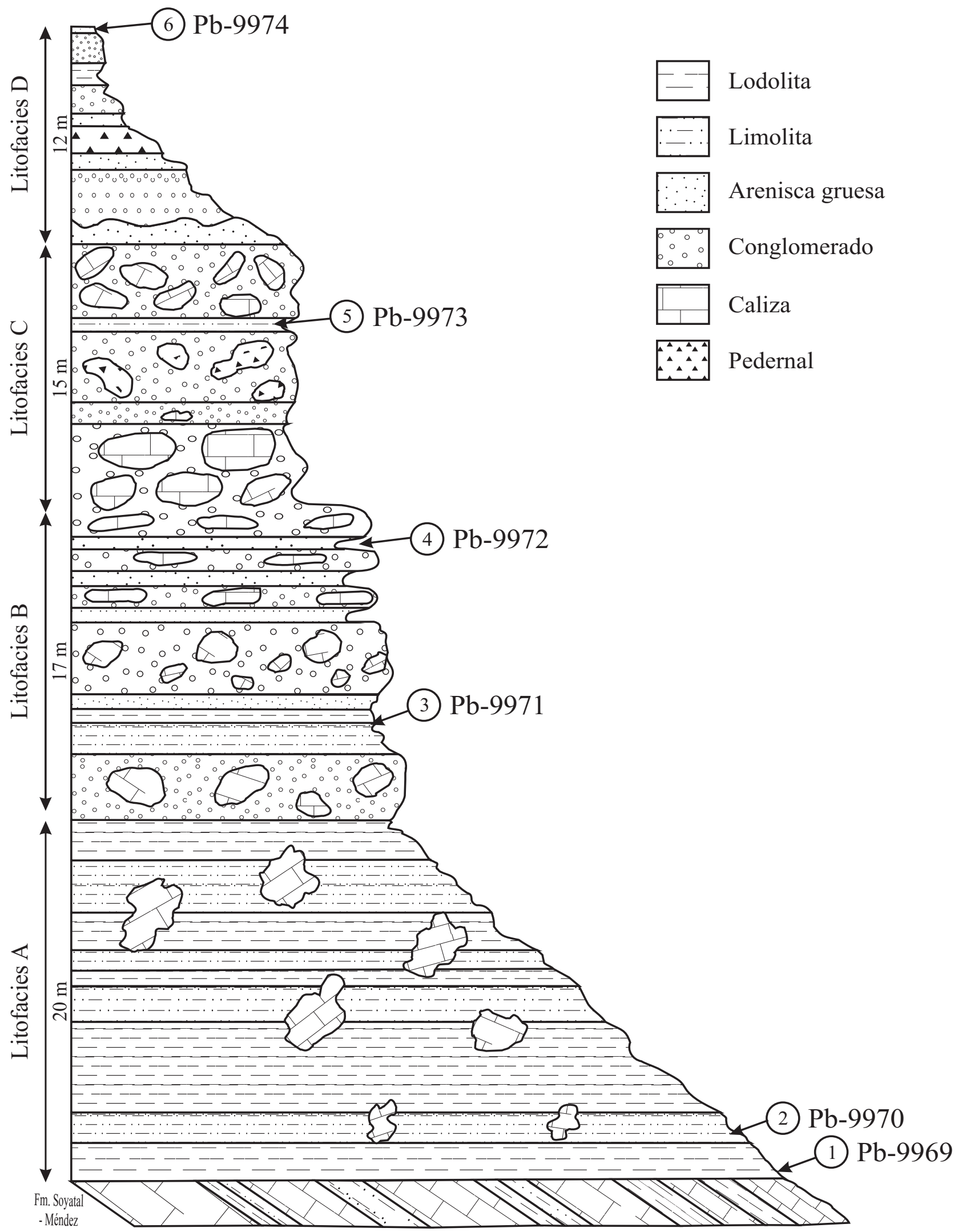

Figura 2. Sección estratigráfica en el cerro El Morro de la localidad tipo de la Formación El Morro (64 m), se divide en cuatro litofacies, la (A) litofacies de avalancha de rocas de $20 \mathrm{~m}$, (B) litofacies de bloques soportados en una matriz de $17 \mathrm{~m}$, (C) soportados entre sí, con bloques estratificados horizontales de $15 \mathrm{~m}$, y (D) clastos soportados entre sí, con gradación inversa de $12 \mathrm{~m}$. 
contaron 500 palinomorfos por muestra, para el análisis de frecuencias palinológicas.

Los conjuntos palinológicos presentan poca diversidad (Figuras 3, 4, 5 y 6) y su significado cronoestratigráfico se basa en las frecuencias relativas de ciertos taxa (biozonas de apogeo), cabe mencionar que la mayoría de los palinomorfos recuperados presentan alcances estratigráficos amplios y solo algunos taxa presentan hemerozonas más restringidas, reportados previamente para el Paleógeno de Norteamérica.

Tomando en consideración la abundancia relativa de ciertos taxa como Alnus, Quercoidites, Pinuspollenites y Tubulifloridites (Figura 5), la edad de la Formación El Morro se podría asumir para estos conjuntos palinológicos como Paleógeno tardío; pero tomando en consideración el fechamiento radiométrico de $38.1 \pm 1.4 \mathrm{Ma}$, que corresponde al Eoceno superior, implica una primera radiación de este tipo de flora para el Eoceno en México, contrastando con el resto de Norteamérica donde dichas zonas acme han sido establecidas para el Oligoceno, como Quercoidites, Pinuspollenites y aun Mioceno para Tubulifloridites. (Leopold y Macginitie, 1972).

Esta cronoestratigrafia también se refuerza por la presencia de fósiles índices como Milfordia Figura 5: D), Cicatricosisporites (Figura 4: A), Verrucingulatisporis (Figura4: E) y Myrtaceidites (Figura 5: C), que caracterizan el Paleógeno de Norteamérica (Frederiksen, 1980).

El conjunto palinológico, también se caracteriza por la presencia de testas de tecamibinos: Arcella sp. (Figura 6), que representan protozoarios muy importantes en los ecosistemas terrestres, tanto en lagos como en cienegas y turberas en donde abunda el musgo conocido como Sphagnun spp., que en los conjuntos palinológicos está representado por los generos Steriosporites y Verrucingulatisporis (Figura 4), (Doring et al., 1966; Gilbert y Mitchell, 2006).

\section{Discusión}

5.1. Consideraciones acerca de la edad de la Formación El Morro

Simons y Mapes (1957), mencionan que existen rocas litológicamente similares en distintos lugares de México: El Cuarenta, Durango; El Oro, México; Tlalpujahua, Michoacán; Zacatecas, Zacatecas y en Guanajuato, Guanajuato. Consideraron que: “debido a la semejanza del conglomerado rojo de Guanajuato con el fanglomerado El Morro, por lo que se refiere a sus relaciones con las rocas Mesozoicas plegadas sobre las que descansa y a las rocas volcánicas casi horizontales encima del conglomerado, al color de la matriz, a la posición de los estratos y a la historia estructural o tectónica, se cree hay correlación entre las edades de las dos formaciones. Por lo tanto, el fanglomerado El Morro es probablemente de las postrimerías del Eoceno y principios del Oligoceno". Adicionalmente des- criben que encima del fanglomerado El Morro hay interdigitaciones locales con lavas andesíticas, y hay fragmentos de esta andesita en conglomerado calcáreo.

Subsecuentes a la descripción de Simons y Mapes (1957) en Zimapán, hubo otros estudios en el área que siguieron los mismos conceptos estratigráficos: Segerstrom (1961), García y Querol (1991) e Yta y Moreno-Tovar (1997).

El estudio JICA-CRM (1980) cita textualmente: "se encuentran cantos de andesita en el conglomerado El Morro. Se considera que el tiempo más antiguo de la actividad volcánica de naturaleza andesítica fue el Eoceno tardío tomando en consideración la edad absoluta determinada en la presente investigación por K-Ar".

Considerando la determinación de la edad isotópica por K-Ar de 38.1 \pm 1.4 Ma, del estudio JICA-CRM, la edad de la cima de la Formación El Morro es del Eoceno tardío.

La actividad de los movimientos laramídicos en México al parecer no fue sincrónica, se tienen registros estratigráficos de que algunas cobijaduras que se desarrollaron en la cuenca de Veracruz en el fondo marino ocurrieron durante el Eoceno medio (Mossman y Viniegra, 1976).

En el frente tectónico de la Sierra Madre Oriental desde las inmediaciones de Parral, Chih. y puntos intermedios hasta Teziutlán, Pue., según Eguiluz et al. (2000) hay diferentes edades de la deformación, pero se inclinan a considerar que pudo ocurrir durante el Eoceno superior.

Entre las cuencas continentales vinculadas con las etapas terminales de la orogenia Laramide y la sedimentación temprana postcretácica, están las del paleógeno en la Mesa Central (Alaniz-Álvarez y Nieto-Samaniego, 2005), y las de la región sur de la Faja Volcánica Transmexicana (Morán-Zenteno et al., 2005).

En la Mesa Central la discordancia Mesozoico-Terciario según Nieto-Samaniego et al. (2005) puede abarcar un lapso que va del Cretácico Superior al Paleoceno en la parte occidental, y del Maastrichtiano al Paleoceno en la parte oriental y representa un hiatus sedimentario ocurrido durante la fase orogénica laramídica. Los sedimentos continentales tienen espesores variables desde decenas a cientos de metros en distancias cortas, con edades probables del depósito de entre el Eoceno temprano y parte del Eoceno medio, sin descartar que parte de ellos sean del Paleoceno.

La primer datación directa de las fallas en el margen oriental de la plataforma de Valles-San Luis Potosí fue hecha por Suter (1984) en las Cabalgaduras de Lobo-Ciénega y La Misión, las cuales son cortadas por rocas plutónicas con una edad de 62.2 $\pm 1.5 \mathrm{Ma}$ (Paleoceno) por el método de $\mathrm{K} / \mathrm{Ar}$, lo que indica la edad mínima de su actividad.

El inicio de los movimientos laramídicos según Suter (1984, 1990), se manifiesta en la Formación Agua Nueva con la formación de estilolitos tectónicos subverticales, y en la Formación San Felipe por pliegues sinsedimentarios originados, en ambos casos por los esfuerzos tectónicos a escala regional. 


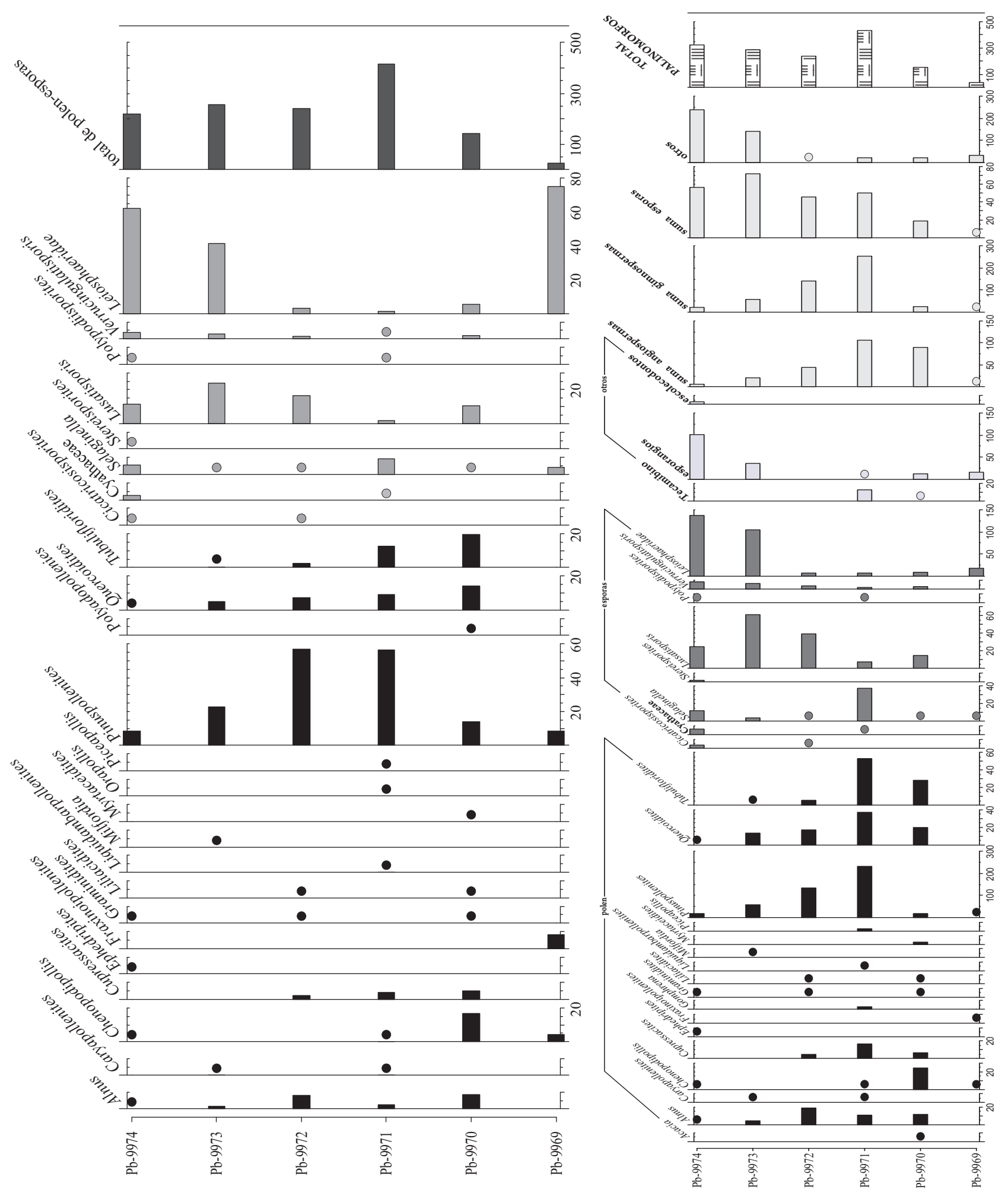

Figura 3. Espectro palinológico de las muestras analizadas en la sección "El Morro". Cada barra corresponde a conteo total. 

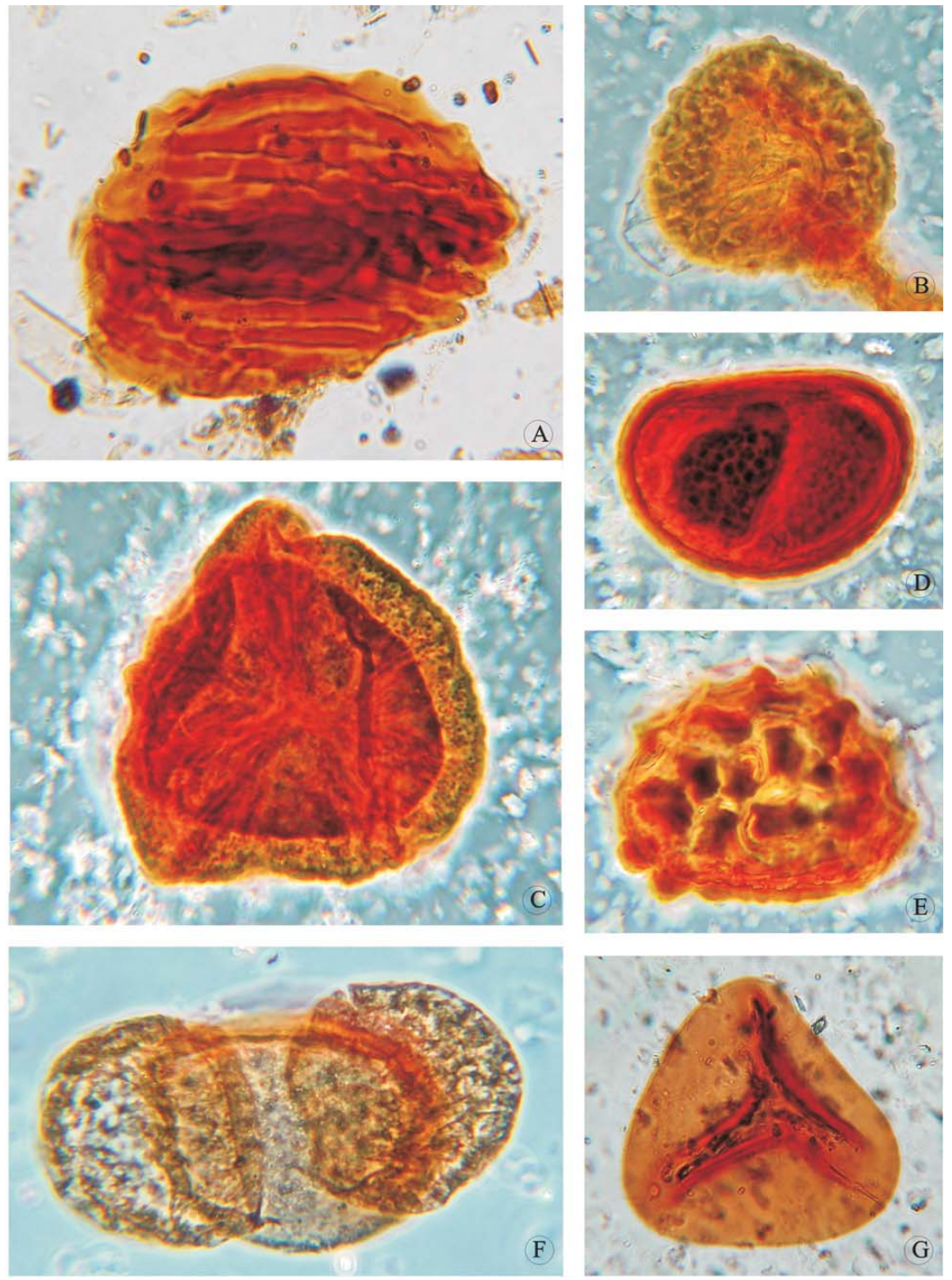

Figura 4. Todas las figuras X 1000 aumentos, un milímetro equivale a una micra. A, Cicatricosisporites; B, Stereisporites; C, Selaginella; D, Polypodiidporites; E, Verrucingulatisporis; F, Pinuspollenites; G, Cyathaceae.

Más recientemente Gray et al. (2001), fecharon ilita diagénetica por el método K-Ar para la determinación de la edad geológica del movimiento en la cabalgadura Jiliapan-El Volantín a $25 \mathrm{~km}$ al norte de Zimapán, concluyeron que dicha deformación es del Paleoceno inferior.

Según Gray et al. (2001), en una roca sedimentaria la ilita diagenética se forma en un ambiente de 80 a $120^{\circ} \mathrm{C}$, y para la dispersión del argón hay una temperatura de cierre de entre 250 y $300{ }^{\circ} \mathrm{C}$. Si en la roca sedimentaria hay un calentamiento generado durante los movimientos en la formación de un plano de falla por encima de los $80{ }^{\circ} \mathrm{C}$, pero por debajo de la temperatura de cierre de dispersión del argón; entonces la edad radiométrica de la ilita diagenética debe ser igual a la edad media de aquel evento de calentamiento estructural donde se formó la ilita diagénetica.
Gray et al. (2001) tomaron la muestra (49b) de ilita diagenética de una ranura del plano de la cobijadura Jiliapán-El Volantín, obtuvieron una edad de $62 \pm 1.7 \mathrm{Ma}$, $\mathrm{y}$ concluyeron que dicha deformación estuvo activa al menos hasta el Paleoceno temprano.

Carrillo-Martínez et al. (2001) especifican que la deformación laramídica del sur de la cuenca de Zimapán, ocurrió entre el Maastrichtiano Inferior y el Eoceno Medio, tomando como base datos paleontológicos y radiométricos.

Para Alaniz-Álvarez y Nieto-Samaniego (2005) la edad de la orogenia Laramide en la parte sur de la plataforma Valles-San Luis Potosí se situó entre el CampanianoMaastrichtiano y $43 \mathrm{Ma}$ (Eoceno medio-inferior) que es la edad del granito postectónico más antiguo emplazado 

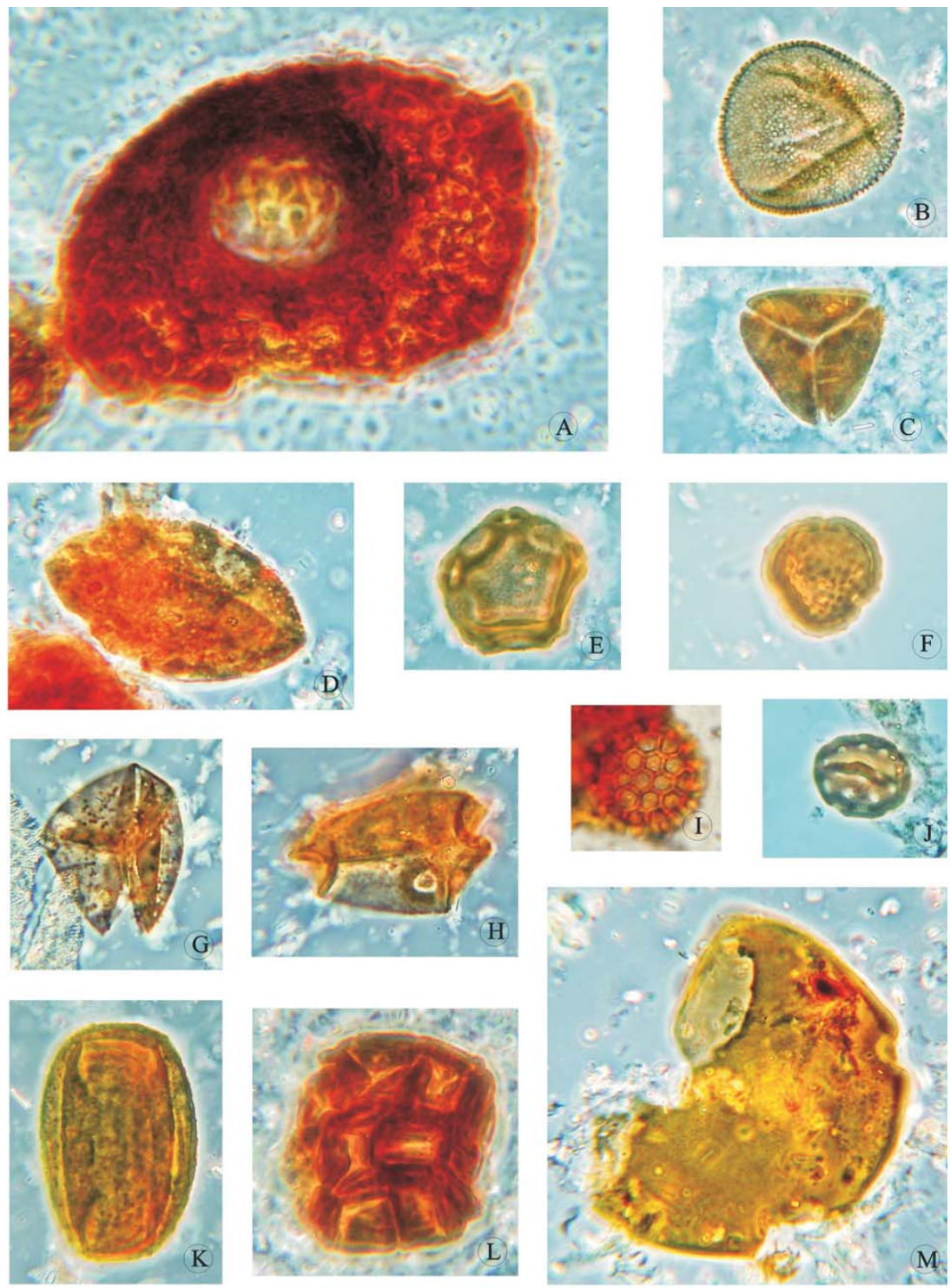

Figura 5. Figura A X 400 aumentos, figuras B-M X 1000 aumentos, un milímetro equivale a una micra. A, Arcella sp.; B, Liliacidites; C, Myrtaceidites; D, Milfordia; E, Alnus; F, Tubulifloridites; G, Cupressacites; H, Graminidites; I,Gomphrena ; J, Chenopodipollis; K, Quercoidites; L, Acacia; M, Caryapollenites.

sobre los sedimentos plegados (Vasallo et al., 2004; cita de Alaniz-Álvarez y Nieto-Samaniego, 2005).

En consecuencia, si las edades determinadas por $\mathrm{Su}-$ ter (1984) y Gray et al. (2001) son las más cercanas a la deformación activa en Zimapán, entonces los primeros sedimentos continentales, son posteriores al Paleoceno temprano.

Con los datos de la edad de la Formación Las Espinas (JICA-CRM, 1980) y el movimiento de la cobijadura Jiliapán-El Volantín (Gray et al., 2001) la edad de la Formación El morro queda al menos restringida al Paleoceno medio-Eoceno medio.

\section{Sedimentología}

En la localidad tipo de la Formación El Morro (cerro El Morro), (Figura 7) el espesor de la columna es de $64 \mathrm{~m}$. y cubre a las rocas de las Formaciones Soyatal-Méndez en discordancia angular de $48^{\circ}$ aproximadamente, la cima de la columna no esta cubierta por las rocas ígneas de la Formación Las Espinas, que probablemente fueron erosionadas, no obstante, a $200 \mathrm{~m}$ al suroeste en la parte inferior del cerro de las Espinas están expuestas las brechas andesíticas básales de la Formación las Espinas, y se observa el contacto entre las dos unidades (Figuras 8 y 9).

En la sección estratigráfica (Figura 2) se describen y clasifican en litofacies de acuerdo a los criterios de Miall 

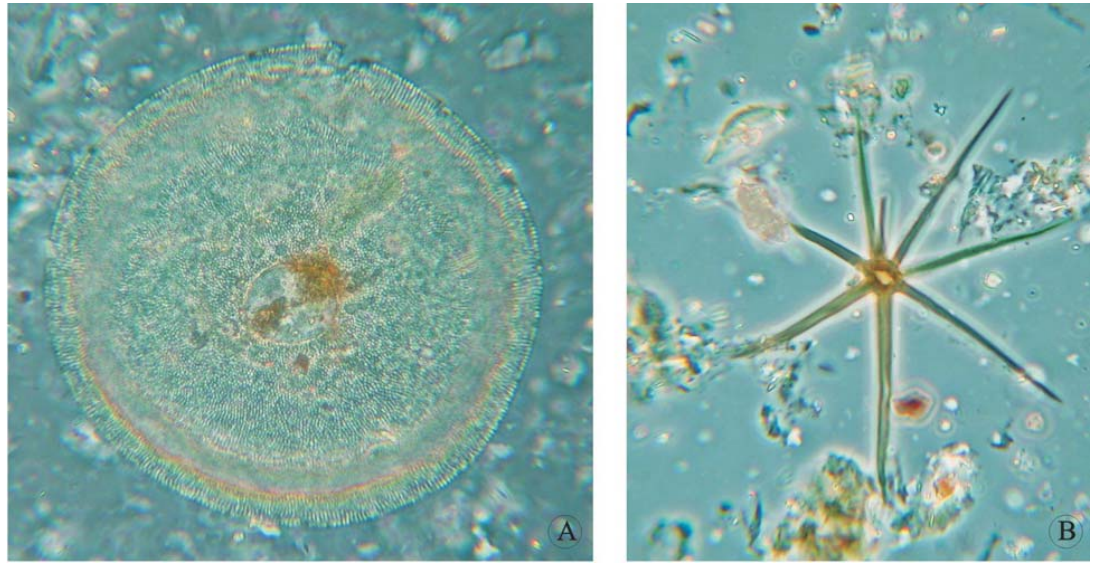

Figura 6. A, Tecamibino X 400 aumentos; B, tricoma, X1000 aumentos.

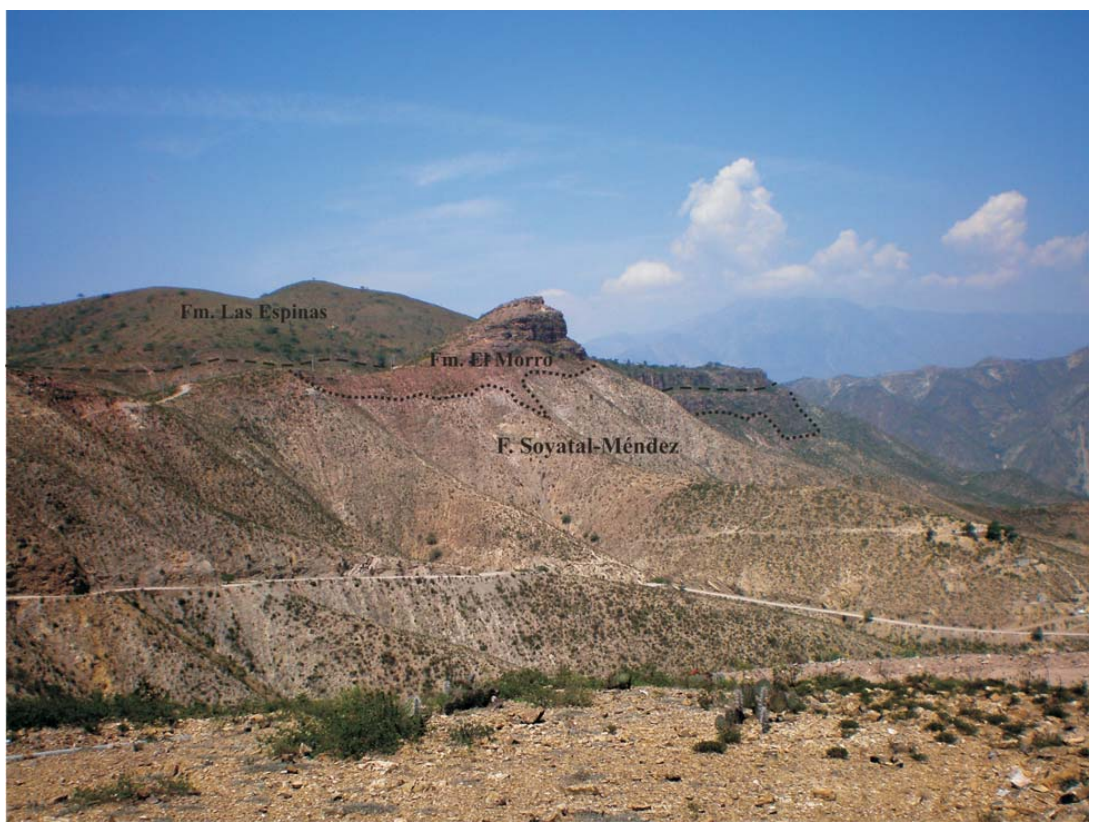

Figura 7. Vista desde Detzani hacia el noroeste del cerro El Morro.

(1996) para los depósitos fluviales, y de Blair y McPherson (1994) para los depósitos aluviales. De acuerdo a Blair y McPherson (1994) los criterios de Miall $(1992,1996)$ y otros investigadores no permiten la distinción real entre sedimentación en abanicos aluviales y fluviales; para la descripción petrográfica de las rocas detríticas y las carbonatadas se utilizan las clasificaciones de Folk (1962) y Folk et al. (1970).

Los espesores de las litofacies diferenciadas son de $20,17,15$, y 12 m respectivamente; cada litofacies tiene características litológicas peculiares relacionadas con la roca madre de donde proceden sus componentes clasticos, su forma de transporte y de depósito. Cada una de estas litofacies muestra así mismo en sus afloramientos. morfologías distintas.

Litofacies A de avalancha de rocas (Blair y McPherson, 1994) $(20 \mathrm{~m})$ : descansa en contacto angular sobre la Formación Soyatal-Méndez (Rumbo N $33^{\circ}$ E, echado hacia el NW de $42^{\circ}$ ) no se observa estratificación, el conjunto tiene una topografía de pendiente suave con una coloración rojiza-gris claro.

Esta litofacies consiste en el depósito de una megabrecha con un $20 \%$ de bloques angulares de un metro y cantos también angulares con los caracteres litológicos de la Formación Méndez (gris verdoso levemente rojizo), soportados en limolita gruesa y calclitarenita fina, inma- 


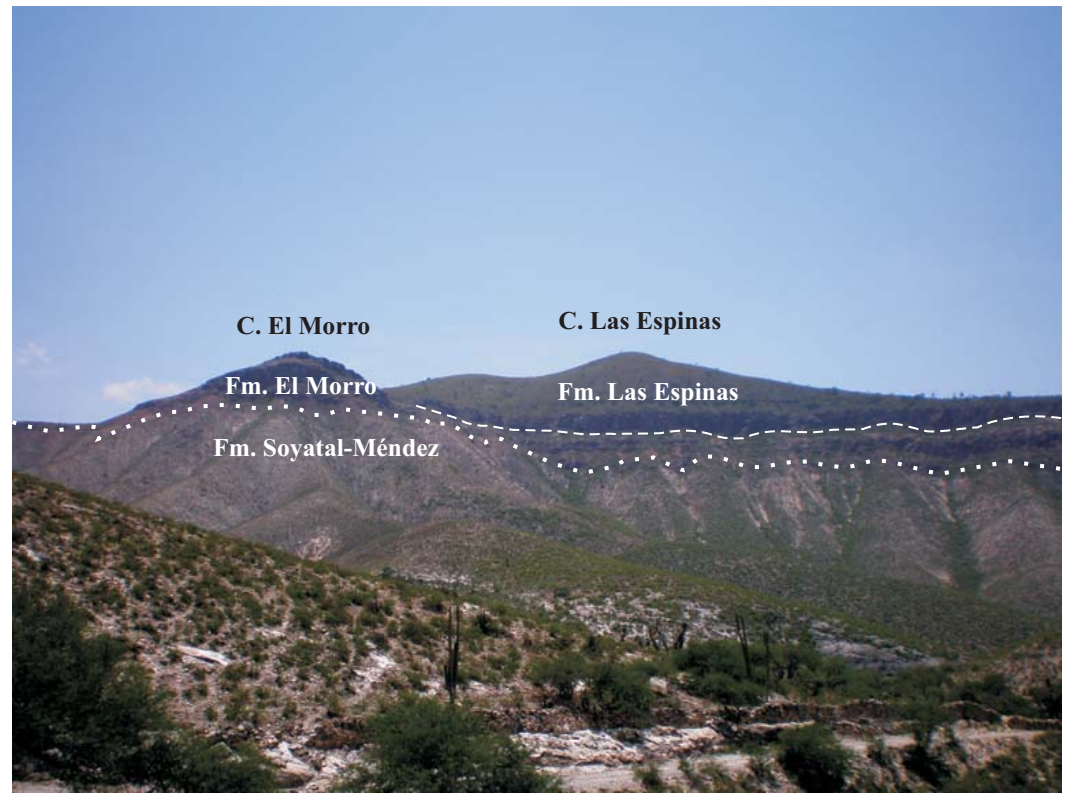

Figura 8. Vista norte-sur desde Dedhó, de los cerros El Morro y Las Espinas, y los contactos entre las Formaciones Soyatal-Méndez, El Morro y Las Espinas.

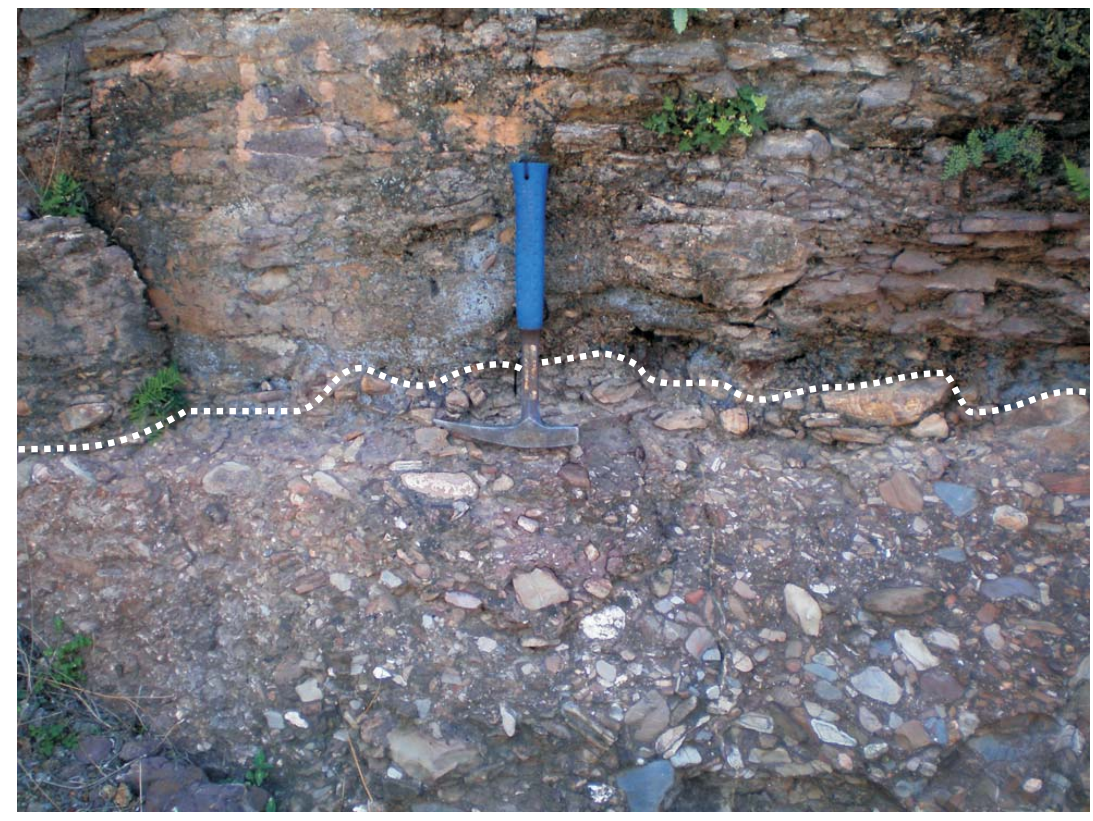

Figura 9. Contacto entre las Formaciones El Morro (inferior) y Las Espinas (superior), en la base del cerro Las Espinas (14Q0455475, 2296053, 1898). Longitud del martillo $0.32 \mathrm{~m}$.

dura, mal seleccionada, y un $20 \%$ de fracción arcillosa de composición calcárea; todo el conjunto litológico esta mal seleccionado e inmaduro (Figura 10), y carece de cementación.

Litofacies B de bloques soportados en una matriz (Miall, 1996: Gmm y Gmg) (17 m): tiene estratos de 3 a $5 \mathrm{~m}$, forma una topografía ligeramente escarpada, la coloración es rojiza; en general presenta estratificación gruesa
(Rumbo N $45^{\circ} \mathrm{W}$, echado hacia el SW de $6^{\circ}$ ). El contacto con la litofacies de avalancha es abrupto con un contraste en la topografía. Es un conglomerado matriz-soportado que en su base tiene un $25 \%$ de guijarros y bloques, subangulares y subredondeados, suspendidos irregularmente en una matriz de gránulos y arena gruesa calcárea; los clastos proceden de la Formación Soyatal, en la parte superior hay lentes delgados e irregulares de limolita y arena gruesa 


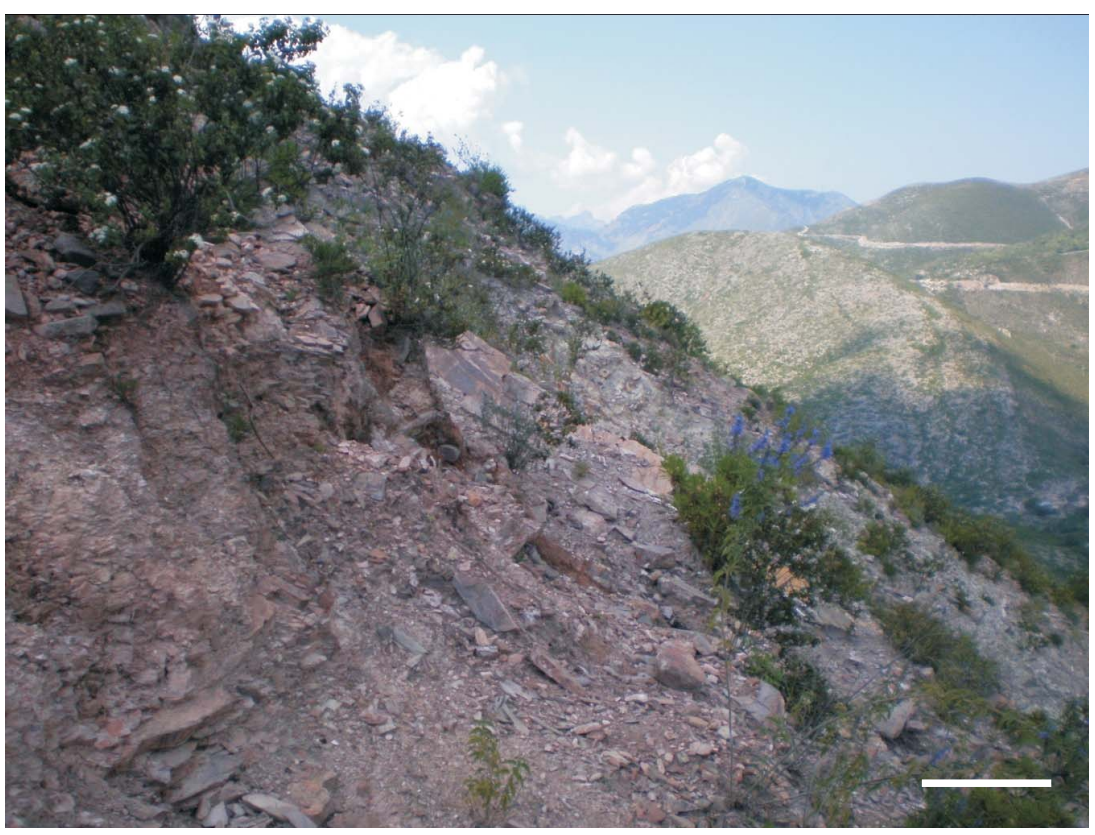

Figura 10. Litofacies A. Bloques angulares de $1 \mathrm{~m}$, y cantos procedentes de la Formación Méndez, contenidos en una matriz de limolita gruesa y calcarenita fina. Longitud de la escala $0.75 \mathrm{~m}$.

calcáreas, con planos poco definidos de estratificación cruzada. La parte media de la litofacies tiene un cuerpo de calclitarudita de guijarros redondeados, suspendidos en una matriz calcárea arenosa gruesa; hay una gradación inversa incipiente; los clastos proceden de la Formación Soyatal, y conservan un color gris, la matriz es gris rojiza. La parte superior (Figura 11) está formada por bloques alargados de $40 \mathrm{~cm}$ de longitud y $15 \mathrm{~cm}$ de ancho, subangulares, que formaron parte de la Formación Soyatal; una característica es que los bloques están en posición horizontal, paralela a la estratificación, soportados en una matriz de cantos y gránulos calcáreos subangulares, de la misma litología de los bloques.

Litofacies $\mathrm{C}$ de clastos soportados entre sí, con bloques estratificados horizontales (Miall, 1996: Gh) (15 m): tiene estratos de 3 a $7 \mathrm{~m}$; el cuerpo basal está formado por calclitarudita de bloques redondeados, ovalados de hasta $40 \mathrm{~cm}$, alineados estratigraficamente en forma horizontal, están suspendidos en cantos y gránulos; los tres tamaños de clastos proceden de la Formación Tamaulipas Superior (micrita fosilífera de foraminíferos planctónicos, Figura 12) y son de un color gris claro; hacia arriba de él existe calclitarudita con bloques de $25 \mathrm{~cm}$ alargadossubredondeados, alineados en forma horizontal con respecto a los planos de estratificación; están suspendidos en cantos y gránulos también procedentes de la Formación Tamaulipas Superior. El cuerpo medio de esta litofacies tiene los estratos más gruesos de todo el conjunto y se caracteriza por formar paredes verticales, la litología es un poco diferente de las rocas que le subyacen; está formada por calclitarudita de cantos y gránulos subredondeados grises, tiene de 10 a $20 \%$ de cuarzo de aspecto lechoso subangular, intercalado irregularmente con pedernalrudita con gránulos angulares de pedernal negro; los clastos de roca carbonatada y el pedernal proceden de la Formación Tamaulipas Superior. La composición mineral mixta de pedernal y cuarzo da más resistencia a la erosión y forma paredes verticales, en la parte superior hay un horizonte de limolita y lutita calcárea de $10 \mathrm{~cm}$ que interrumpe la topografía vertical. El cuerpo superior está formado por calclitarudita de bloques redondeados, ovalados de hasta $40 \mathrm{~cm}$, alineados estratigraficamente en forma horizontal, están suspendidos en cantos y gránulos; los tres tamaños de clastos proceden de la Formación Tamaulipas Superior y son de un color gris claro, este cuerpo es semejante al de la base de la litofacies.

Litofacies D de clastos soportados entre sí, con gradación inversa (Miall, Gci) (12 $\mathbf{~ m})$ : esta litofacies es menos resistente a la erosión que la anterior y forma pendientes suaves, tiene dos cuerpos de roca; el inferior se caracteriza por calclitarenita gruesa intercalada con calclitarudita de cantos (grises) ovalados y redondeados, alineados en forma horizontal, con gradación inversa; se observan manchones de calcita cristalina, los cuales fueron formados por la influencia de un dique de $40 \mathrm{~cm}$ de monzonita que corta en forma oblicua los estratos. El cuerpo superior se caracteriza de una intercalación de pedernalrudita de gránulos, con calclitarenita gruesa, y con calclitarudita de cantos redondeados suspendidos en gránulos. Los clastos de pedernal y de roca carbonatada proceden de la Formación Tamaulipas Superior. 


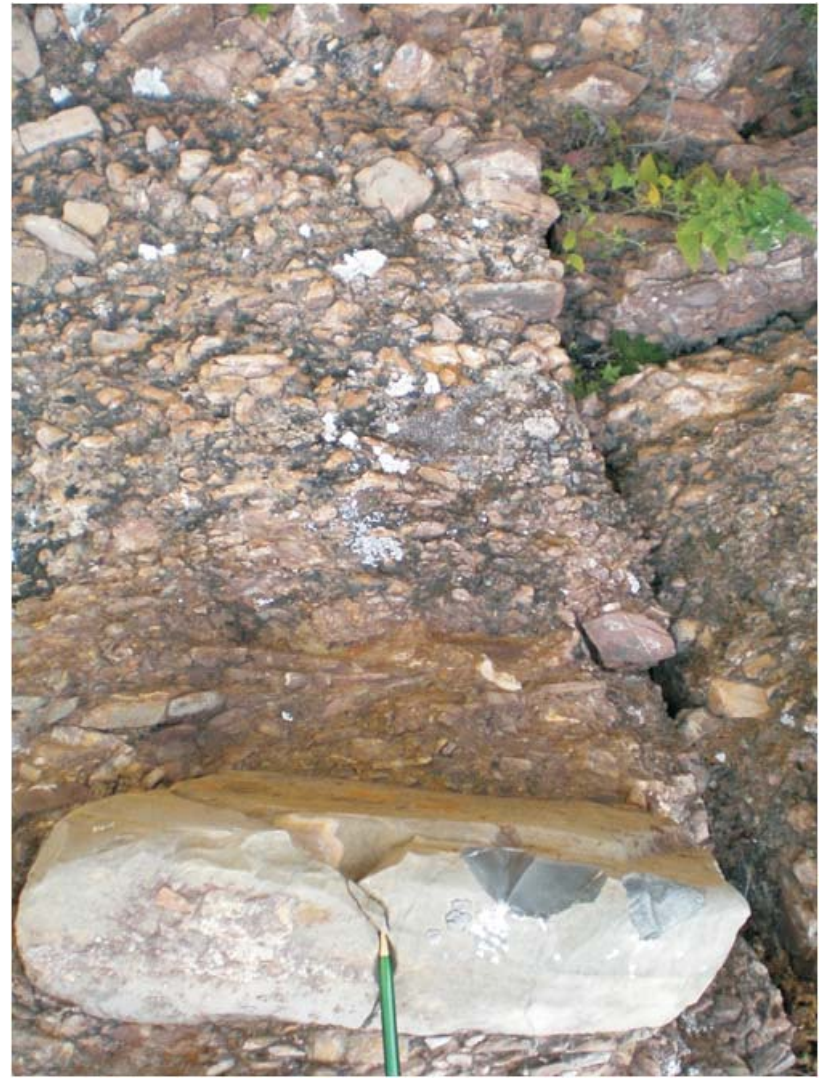

Figura 11. Litofacies B, parte superior. Bloques alargados horizontales de $40 \mathrm{~cm}$ de longitud, subangulares, que formaron parte de la Formación Soyatal; en una matriz de cantos y gránulos calcáreos. Longitud parcial de la pluma $0.10 \mathrm{~m}$.

Las cuatro litofacies indican que la construcción del sistema sedimentario en el cerro El Morro atravesó por varias etapas, en las que las fuentes de los sedimentos fueron diferentes.

En el registro geológico mundial los sedimentos relacionados con procesos aluviales del Precámbrico, Devónico, Carbonífero al Jurásico, Cretácico y Cenozoico comúnmente están asociados a los cinturones postorogénicos; Nilsen (1982) considera que la prolongación del levantamiento de las montañas postorogénicas impide la preservación estratigráfica completa de este tipo de conglomerados continentales.

Morán-Zenteno et al. (2005) hicieron notar que en la región sur de Faja Volcánica Transmexicana la acumulación de secuencias continentales en las cuencas se conserva sólo localmente.

En el caso especifico de la sección del cerro del Morro las cuatro litofacies que constituyen la Formación El Morro, están ligadas a tres fuentes de sedimentos con características litológicas distintas. En la litofacies de avalancha de rocas, las rocas de la Formación Méndez aportaron material, en la litofacies de bloques soportados en una

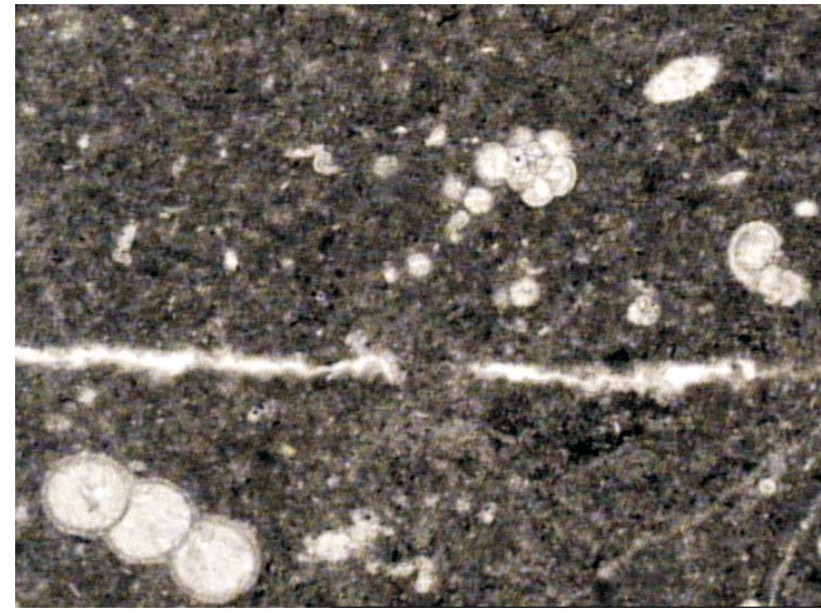

Figura 12. Litofacies C. Petrografía de los clastos que proceden de la Formación Tamaulipas Superior, formada por micrita fosilífera de foraminíferos planctónicos.Ancho real de la fotografia $0.8 \mathrm{~mm}$.

matriz la Formación Soyatal, y en las litofacies de clastos soportados entre sí, con bloques estratificados horizontales y la de clastos soportados entre sí, con gradación inversa la Formación Tamaulipas Superior.

La sedimentación en la litofacies de avalancha de rocas que es la más antigua, es caótica y desorganizada, con características de inmadurez textural en los bloques y cantos angulosos derivados de la Formación Méndez, los cuales son sostenidos por una matriz de limolita gruesa, calclitarenita fina angulosa de aspecto granular, y una fracción arcillosa de composición calcárea. Los caracteres litológicos indican que el depósito se formó por el desprendimiento de rocas fracturadas, que sufrieron una caída catastrófica que dio lugar a una desintegración y pulverización que formo una masa granular al frente de una montaña.

La litofacies de bloques soportados en una matriz tiene un contacto abrupto con la litofacies subyacente de avalancha de rocas. En esta litofacies la redondez de los bloques, guijarros, cantos y gránulos, varía de subangular a subredondeada, y proceden de la Formación Soyatal que es una roca más 'dura' en comparación con la Formación Méndez. El mecanismo de transporte fue probablemente por flujo de escombros (debris flow) como lo sugieren los bloques soportados en una matriz, así como la alineación horizontal de bloques alargados paralelos a la estratificación. Probablemente toda esta litofacies se deposito sobre parte de la topografía preexistente de un pequeño abanico aluvial, o bien fue parte de la sedimentación en el flanco de un abanico mayor, de una forma o de otra fueron necesarias ciertas condiciones de transporte acuoso, para formar un flujo de escombros y una alineación horizontal de los bloques.

La litofacies de clastos soportados entre sí, con bloques 
estratificados horizontales está formada por clastos de la Formación Tamaulipas Superior redondeados a subredondeados, con tamaños variables entre bloques, cantos y gránulos, casi siempre los cantos y gránulos forman una matriz que sostiene a los bloques con diversas orientaciones, predominando la horizontal; la intercalación de calclitarudita de cantos y gránulos, con pedernalrudita de gránulos angulares y cuarzo de aspecto lechoso subangular, sugieren que todos los clastos tuvieron un transporte por agua, que propició la redondez de los clastos de roca carbonatada, el desprendimiento del pedernal de la roca carbonatada, su traslado hasta formar gránulos angulares (el pedernal no puede alcanzar redondez por su estructura microcristalina), y la anexión de cuarzo lechoso subangular, procedente de alguna veta vecina. Las características anteriores indican que hubo un transporte acuoso, y un depósito que propicio el alineamiento horizontal de los bloques.

La litofacies de clastos soportados entre sí, con gradación inversa marca una disminución en el tamaño de los clásticos, con respecto a las tres unidades que le subyacen; el tamaño mayor es de cantos redondeados y el menor de calclitarenita gruesa. El hecho de que haya una intercalación de pedernalrudita de gránulos con calclitarenita y calclitarudita señala que hubo un nivel de energía que movió estas partículas, las redondeo y las separo, fueron transportadas por un flujo laminar o turbulento.

\section{Conclusiones}

Las características estratigráficas y sedimentológicas que presenta la secuencia de sedimentos continentales de la Formación El Morro son típicas de una sedimentación postlaramídica en cuencas intermontanas.

La edad de la Formación El Morro es limitada al Paleoceno medio-Eoceno medio mediante la edad isotópica por K-Ar de las rocas volcánicas suprayacentes y la ilita formada en el movimiento de la cobijadura Jiliapán-El Volantín.

Los sedimentos de la Formación El Morro se formaron bajo condiciones aluviales y fluviales, las cuatro litofacies están formadas por sedimentos procedentes de la erosión de las Formaciones Mendez, Soyatal y Tamaulipas Superior.

La palinología indica un ambiente sedimentario continental fluvial caracterizado por cuerpos acuosos y ciénegas, típicos de un clima tropical húmedo, los cuales fueron interrumpidos por las avalanchas de roca y las caídas catastróficas de bloques, y además los flujos de escombros que acompañaron a las avalanchas. La edad relativa de los palinomorfos sugiere una edad del Eoceno medio al Eoceno tardío.

\section{Referencias bibliográficas}

Alaniz-Álvarez, S.A., Nieto-Samaniego, A.F., 2005, El sistema de fallas Taxco-San Miguel de Allende y la Faja Volcánica Transmexicana, dos fronteras tectónicas del centro de México activas durante el Cenozoico: Boletín de la Sociedad Geológica Mexicana, 57, 65-82.

Andersen, D.W., Picard, M.D., 1973, Tectonics and depositional history of Rocky Mountain Intermontane Basin: American Association of Petroleum Geologists, 58 annual meeting, abstracts, 767.

Blair, T.C., McPherson, J.G., 1994, Alluvial fans and their natural distinction from rivers based on morphology, Hydraulic processes, sedimentary processes and facies assemblages: Journal of Sedimentary Research, A64, 450-489.

Böse, E., 1923, Vestiges of an ancient continent in Northeast Mexico: American Journal of Science, 6, 127-196.

Cantagrel, J.M., Robin, C., 1979, K-Ar dating on Eastern Mexican Volcanic Rocks relations between the andesitic and the alkaline provinces: Journal of Volcanology and Geothermal Research, 5, 99-114.

Carrillo-Martínez, M., 1998 (2000), Resumen de la geología de la hoja Zimapán, estados de Hidalgo y Querétaro: Carta geológica de México, Instituto de Geología, UNAM, Hoja Zimapán 14Q-e(7), texto explicativo, $33 \mathrm{p}$.

Carrillo-Martínez, M. Suter, M., 1982, Tectónica de los alrededores de Zimapán, Hidalgo y Querétaro: Sociedad Geológica Mexicana, VI Convención Geológica Nacional, Libro-guía de la excursión geológica a la región de Zimapán y área circundantes, Estados de Hidalgo y Querétaro, 1-20.

Carrillo-Martínez, M., Valencia, J.J., Vázquez, M.E., 2001, Geology of the Southwestern Sierra Madre Oriental fold-and-thrust belt, eastcentral Mexico: in Bartolini, C., Buffler, R.T., Cantú Ch., A., eds., The Western Gulf of México Basin, Tectonics, Sedimentary Basins, and Petroleum Systems: American Association of Petroleum Geologists, Memoir, 75, 145-158.

Consejo de Recursos Minerales (CRM), 1992, Monografía Geológica Minera del estado de Hidalgo: Pachuca, Hidalgo, Consejo de Recursos Minerales, $95 \mathrm{p}$.

Doring, H. Von, Krutzsch, W., Schulz, E., Timmermann, E., 1966, Über einige neue subformgenera der Sporengattung Stereisporites Th. \& Pf. Aus dem Mesozoikum und Alttertiar mitteleropas: Geologie, Jahrgang 15, Beiheft 55, 72-83.

Edwards, J.D., 1955, Studies of some early Tertiary red conglomerates of central Mexico: Geological Survey Professional Paper, 264-H, 153-183.

Eguiluz-de Antuñano, S., Aranda-García, M., Marrett, R., 2000, Tectónica de la Sierra Madre Oriental, México: Boletín de la Sociedad Geológica Mexicana, 53, 1-26.

Ferrusquía, I., 1987, Reubicación geocronológica del Conglomerado Guanajuato basada en nuevos mamíferos: Universidad Nacional Autónoma de México, Instituto de Geología, Simposio sobre la geología de la región de la Sierra de Guanajuato, Guanajuato, Gto., Programa, resúmenes y guía de excursión, 21-23.

Fries, C. Jr., 1962, Carta geológica de México, Hoja Pachuca, 14-Qe(11): Instituto de Geología, Universidad Nacional Autónoma de México.

Folk, R.L., 1962, Spectral subdivision of limestone types, in Ham, W.H., ed., Classification of carbonate rocks, American Association of Petroleum Geologists, Memoir 1, 62-84.

Folk, R.L., Andrews, P.B., Lewis, D.W., 1970, Detrital sedimentary rock classification and nomenclature for use in New Zealand: New Zealand Journal of Geology and Geophysics, 13, 937-968.

Frederiksen N.O., 1980, Sporomorphs from the Jackson Group (Upper Eocene) and Adjacent Strata of Mississippi and Western Alabama, U.S. Geological Survey Profesional Paper, 75p.

García, G., Querol, F., 1991, Description of some deposits in the Zimapan District, Hidalgo, in Salas, G.P., ed., Economic Geology, Mexico: Boulder, Colorado, Geological Society of America, The geology of North America, P-3, 295-313.

Geyne, A.R., Fries, C. Jr., Segerstrom, K., Black, R.F., Wilson, I.F., 1963, Geología y yacimientos minerales del Distrito de Pachuca-Real del 
Monte, Estado de Hidalgo, México, Consejo de Recursos Naturales No Renovables, Publicación 5E, 22 p.

Gilbert D., Mitchell E.A.D., 2006, Microbial diversity in Sphagnum peatlands, in Martini, I.P., Martínez-Cortizas, A., Chesworth, W., eds., Peatlands: Evolution and records of environmental and climate changes: The Netherlands, Elsevier, 287-318.

Gray, G.G., Pottorf, R.J., Yurewicz, D.A., Mahon, K.I. Pevear, D.R., Chuchla, R.J., 2001, Thermal and chronological record of syn-to postLaramide burial and exhumation, Sierra Madre Oriental, Mexico, in Bartolini, C., Buffler, R.T., Cantú Ch., A., eds., The Western Gulf of México Basin, Tectonics, Sedimentary Basins, and Petroleum Systems: American Association of Petroleum Geologists, Memoir, $75,159-181$.

Japan International Cooperation Agency-Consejo de Recursos Minerales (JICA-CRM), 1980, Report on geological survey of the PachucaZimapán area, central Mexico. Phase I, Metal Mining Agency of Japan and Japan International Cooperation Agency-Consejo de Recursos Minerales, México, 148 p. (inédito, archivo técnico del Servicio Geológico Mexicano.

Leopold, E.B., Macginitie, H.D., 1972. Development and affinities of Tertiary floras in the Rocky Mountains, in Graham, A., ed., Floristics and Paleofloristics of Asia and Eastern North America: Amsterdam, Elsevier, 147-200.

Miall, A.D., 1992, Alluvial deposits, in Walker, R.G., James, N.P., eds., Facies Models: Response to Sea-Level Change: Toronto, Geological Association of Canada, 119-142.

Miall, A.D., 1996, The Geology of Fluvial Deposits: New York, Springer Verlag, $582 \mathrm{p}$.

Morán-Zenteno, D.J., Cerca, M., Keppie, J.K., 2005, La evolución tectónica y magmática cenozoica del suroeste de México: avances y problemas de interpretación: Boletín de la Sociedad Geológica Mexicana, 57, 319-341.

Mossman, R.W. y Viniegra, F., 1976, Complex fault structures in Veracruz province of Mexico: American Association of Petroleum Geologists Bulletin, 60, 379-388.

Nieto-Samaniego, A.F., 1990 (1992), Fallamiento y estratigrafía cenozoicos en la parte sudoriental de la Sierra de Guanajuato: Universidad Nacional Autónoma de México, Instituto de Geología, Revista, vol. 9, 146-155.
Nieto-Samaniego, A.F., Alaniz-Álvarez, S.A. y Camprubí, A., 2005, La Mesa Central de México: estructura y evolución tectónica cenozoica: Boletín de la Sociedad Geológica Mexicana, 57, 285-318.

Nilsen, T.H., 1982, Alluvial fan deposits. in, Scholle, P.A., Spearing, D. eds., Sandstone depositional environments: American Association of Petroleum Geologists, Memoir 31, 49-86.

Segerstrom, K., 1961, Geología del suroeste del estado de Hidalgo y del noreste del estado de México: Boletín de la Asociación Mexicana de Geólogos Petroleros, 13, 147-168.

Servicio Geológico Mexicano, 1997, Carta Geológico-Minera, Pachuca F14-11, Hidalgo, Queretaro, Estado de México,Veracruz y Puebla, escala 1: 250,000: Secretaría de Economía.

Simons, F.S., Mapes-Vázquez, E., 1957, Geología y yacimientos minerales del distrito minero de Zimapán, Hidalgo: Instituto Nacional para la Investigación de Recursos Minerales, Boletín 40, 270 p.

Suter, M., 1984, Cordilleran deformation along the eastern edge of the Valles-San Luis Potosi carbonate platform, Sierra Madre Oriental fold-thrust belt, east-central Mexico: Geological Society of America Bulletin, 95, 1387-1397.

Suter, M., 1990, Geología de la hoja Tamazunchale, estados de Hidalgo, Querétaro y San Luis Potosí: Instituto de Geología, Universidad Nacional Autónoma de México, Hoja Tamazunchale 14Q-e(5), texto explicativo, $54 \mathrm{p}$.

Yta, M., Moreno-Tovar, R., 1997, La mineralización en los distritos mineros Pachuca-Real del Monte y Zimapán-su papel en la evolución metalogénica del Estado de Hidalgo, México: Instituto de Investigaciones en Ciencias de la Tierra, Universidad Autónoma de Hidalgo e Instituto de Geología, Universidad Nacional Autónoma de México, II Convención sobre la Evolución Geológica de México y Recursos Asociados, Pachuca, Hgo., libro-guía de la excursión geológica 3, 73-87.

Manuscrito recibido: 20/01/2009

Manuscrito corregido recibido: 14/08/2009

Manuscrito aceptado: 20/09/2009 